\title{
ON THE WEAKLY CLOSED ALGEBRA GENERATED BY A UNITARY OPERATOR IN A PONTRYAGIN SPACE
}

\author{
VLADIMIR STRAUSS
}

Abstract. This work is devoted to a study of a weakly closed algebra generated by polynomials of a unitary operator in a Pontryagin space. In particular, the inverse operator can belong or not to this algebra. The corresponding criteria is obtained.

Mathematics subject classification (2010): 46C20, 47B50, 47A60, 47L75.

Keywords and phrases: Pontryagin spaces, unitary operators, inverse operator, weakly closed operator algebra.

\section{REFERENCES}

[1] T. Ya. Azizov, I. S. Iokhvidov, Foundation of the Theory of Linear Operators in Spaces with Indefinite, Metric (Russian), Nauka, Moscow, 1986.

[2] T. YA. Azizov, I. S. IokHvidov, Linear Operators in Spaces with Indefinite Metric, (English), Wiley, New York, 1989.

[3] J. Bergh, J. LÖFström, Interpolation spaces. An Introduction, Springer Verlag, New York, 1976.

[4] M. S. BIRMAN, M. Z. SOlOMYAK, Spectral theory of self-ajoint operators in a Hilbert space, (Russian), Leningrad University, Leningrad (USSR), 1980.

[5] O. Bratteli, D. W. Robinson, Operator Algebras and Quantum Statistical Mechanics, Vol. 1, Springer-Verlag, New York, 1979.

[6] N. Dunford, J. T. Schwartz, Linear Operators, General Theory John Wiley \& Sons, New York, 1958.

[7] J. B. Garnett, Bouded Analytic Functions, Academic Press, New York-London-Toronto-SydneySan Francisco, 1981.

[8] A. GHEOndeA, Pseudo-regular spectral functions in Krein spaces, J. of Oper. Th. 12, 1984, 349-358.

[9] P. JONAS, On the functional calculus and the spectral function for defitizable operators in Krein space, Beiträge Anal. 16, 1981, 121-135.

[10] M. G. KREIN, H. LANGER, On the spectral function of a self-adjoint operator in a space with indefinite metric, (Russian), Dokl. Akad. Nauk SSSR 152, 1963, 39-42.

[11] S. G. Krein, Yu. I. Petunin, Ye. M. Semyonov, Interpolation of linear operators, (Russian), Nauka, Moscow, 1978.

[12] H. LANGER, Spectraltheorie linearer Operatoren in J-räumen und enige Anwendungen auf die Shar $L(\lambda)=\lambda^{2} I+\lambda B+C$, Habilitationsschrift, Dresden Tech. Univer., Dresden, 1965.

[13] H. LANGER, Spectral functions of definitizable operators in Krein space, Lect. Not. Math. 948, 1982, $1-46$.

[14] M. A. NAIMARK, Normed Algebras, Wolters-Nordhoff Publishing, Groningen, The Nedherlands, 1972.

[15] M. ReEd, B. Simon, Methods of Modern Mathematical Physics. I: Functional Analysis 2nd Edition, Acad. Press, Inc., 1980.

[16] D. SARASON, Invariant subspaces and unstarred operator algebras, Pacific Journal of Mathematics 17 (3) (1966), 511-517.

[17] V. A. StRauss, Functional representation of an algebra generated by a selfadjoint operator in Pontryagin space, Funktsionalnyi analiz i ego prilozheniya (Russian), English translation: Funct. Anal. Appl. 20 (1) (1986), 91-92. 
[18] V. A. STRAUSS, On an analog of the Wold decomposition for a $\pi$-semi-unitary operator and its model representation, Contemporary Mathematics (USA: AMS) 189, 1995, 473-484.

[19] V. A. STRAUSS, On a structure of a $\pi$-unitary operator and the algebra generated by this operator, Collection "Spectral and evolution problems", UMK VO, Kiev (Ukraine), 1991, 4-6.

[20] V. STRAuSs, A functional description for the commutative $W J^{*}$-algebras of the $D_{K}^{+}$-class, Proceedings: Operator theory and indefinite inner product spaces, Oper. Theory Adv. Appl. 163, Birkhäuser, Basel, 2006, 299-335.

[21] V. STRAUSS, Models of function type for commutative symmetric operator families in Krein spaces, Abst. and Appl. Analysis 2008, Article ID 439781, 2008, 40 p.

[22] J. Wermer, On invariant subspaces of normal operators, Proc. Amer. Math. Soc. 3, 1952, 270-277. 